\title{
Individualizing propofol dosage: a multivariate linear model approach
}

\section{Conceição Rocha, Teresa Mendonça \& Maria Eduarda Silva}

Journal of Clinical Monitoring and Computing

Including a Specialty Section on

Surgical Neuromonitoring

ISSN 1387-1307

Volume 28

Number 6

J Clin Monit Comput (2014) 28:525-536

DOI 10.1007/s10877-013-9510-1
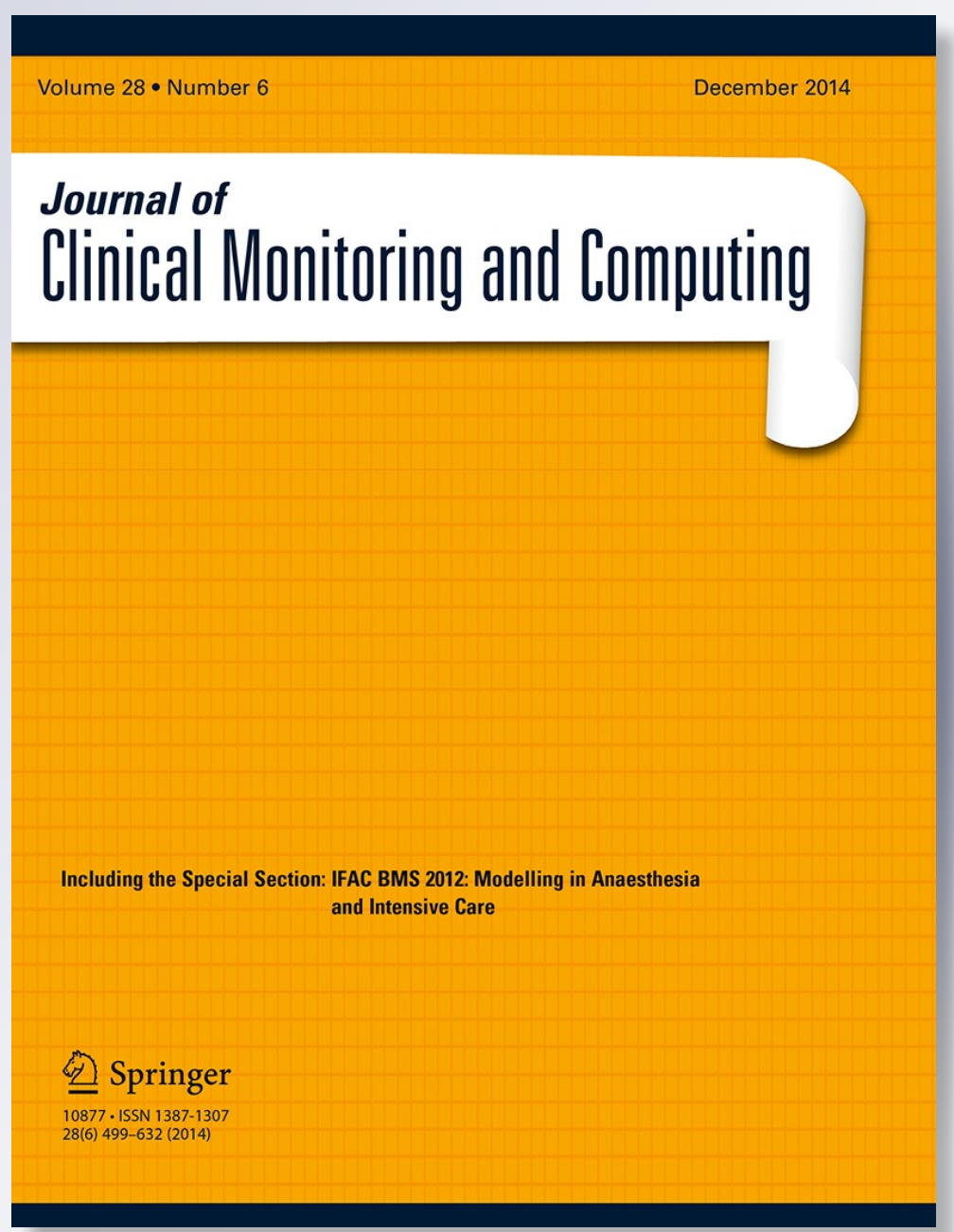

望 Springer 
Your article is protected by copyright and all rights are held exclusively by Springer Science +Business Media New York. This e-offprint is for personal use only and shall not be selfarchived in electronic repositories. If you wish to self-archive your article, please use the accepted manuscript version for posting on your own website. You may further deposit the accepted manuscript version in any repository, provided it is only made publicly available 12 months after official publication or later and provided acknowledgement is given to the original source of publication and a link is inserted to the published article on Springer's website. The link must be accompanied by the following text: "The final publication is available at link.springer.com". 


\title{
Individualizing propofol dosage: a multivariate linear model approach
}

\author{
Conceição Rocha $\cdot$ Teresa Mendonça • \\ Maria Eduarda Silva
}

Received: 30 April 2013/Accepted: 4 September 2013/Published online: 27 September 2013

(c) Springer Science+Business Media New York 2013

\begin{abstract}
In the last decades propofol became established as an intravenous agent for the induction and maintenance of both sedation and general anesthesia procedures. In order to achieve the desired clinical effects appropriate infusion rate strategies must be designed. Moreover, it is important to avoid or minimize associated side effects namely adverse cardiorespiratory effects and delayed recovery. Nowadays, to attain these purposes the continuous propofol delivery is usually performed through target-controlled infusion (TCI) systems whose algorithms rely on pharmacokinetic and pharmacodynamic models. This work presents statistical models to estimate both the infusion rate and the bolus administration. The modeling strategy relies on multivariate linear models, based on patient characteristics such as age, height, weight and gender along with the desired target concentration. A clinical database collected with a RugLoopII device on 84 patients undergoing ultrasonographic endoscopy under sedation-analgesia with propofol and remifentanil is used to estimate the models (training set with 74 cases) and assess their performance (test set with 10 cases). The results obtained in the test set comprising a broad range of characteristics are satisfactory since the models are able to predict bolus, infusion rates and the effect-site
\end{abstract}

C. Rocha $(\bowtie) \cdot$ T. Mendonça

Faculdade de Ciências da Universidade do Porto, Rua do Campo

Alegre, 4169-007 Porto, Portugal

e-mail: mnrocha@fc.up.pt

C. Rocha $\cdot$ T. Mendonça $\cdot$ M. E. Silva

Center for Research \& Development in Mathematics and

Applications (CIDMA), Aveiro, Portugal

M. E. Silva

Faculdade de Economia da Universidade do Porto,

Rua Dr. Roberto Frias, 4200-464 Porto, Portugal concentrations comparable to those of TCI. Furthermore, comparisons of the effect-site concentrations for dosages predicted by the proposed Linear model and the Marsh model for the same target concentration is achieved using Schnider model and a factorial design on the factors (patients characteristics). The results indicate that the Linear model predicts a dosage profile that is faster in leading to an effectsite concentration closer to the desired target concentration.

Keywords Model approximation - Estimation parameters · Regression analysis - Error analysis . Linear prediction $\cdot$ Medical applications

\section{Introduction}

Usually propofol infusions are manually-controlled based upon the posology and the clinician experience. Nevertheless, several methods, algorithms and devices have been proposed in order to obtain a reliable prediction of the dose required to attain a desired effect. Hence, nowadays a computer-assisted target controlled infusion (TCI) device is widely used in the continuous administration of propofol, in a variety of anesthetic procedures and environments. This device is a delivery pump that administers the propofol accordingly to the pharmacokinetic propofol model, assuming averaged parameters derived from population samples and infusion control algorithms [1] in order to obtain a predefined target effect concentration.

There are two adult models for propofol programmed into commercially available TCI pumps, the Marsh model and the Schnider model. In the first one the pharmacokinetic parameters depend on patient weight and is considered suitable to model the plasma propofol concentration. In the Schnider model the pharmacokinetic parameters 
depend not only on patient weight but also on his age, height, gender and lean body mass (LBM) [13]. Based in some studies [10], the Schnider model is recommended to be used for TCI and advisory displays [15].

Several research groups $[5,6]$, have published studies in order to evaluate the accuracy of the TCI system for propofol administration in achieving the desired effect concentration. In particular, [17] and [3] evaluated the behavior of TCI for predicting the propofol dose infusion rate and both works consider its performance acceptable for clinical purposes. Some studies [12,16] compare the clinical profile of TCI of propofol with that of manuallycontrolled infusions but their comparative effectiveness remains controversial [9].

From clinical experience reported in a large number of published analysis, it turns out that a TCI based system for the administration of propofol is highly helpful. Nevertheless, the cost associated with the referred devices alongside with the fact that the delivery algorithm used is not open access, comprise the main restrictions to the wide use of such systems.

Usually the administration of intravenous sedative-hypnotic agents comprehends two steps: an initial bolus of drug, propofol in this case study, followed by a continuous infusion. However, in many situations the target concentration, $C T$, needs readjustment and when its value must be increased an intermediate bolus of drug is administrated. The purpose of this work is to infer both boluses and the subsequent infusion rate from patient characteristics and the desired target concentration using linear models. The models are developed based on a clinical database collected by $\mathrm{Ru}-$ gLoopII on patients undergoing ultrasonographic endoscopy under sedation-analgesia with propofol and remifentanil and rely on patient data (age, height, weight and LBM) and the desired target concentration. The models proposed here present a mean behavior comparable to that of a TCI system and may be considered a step forward to the definition of a simple model for estimating propofol individualized dosage based on patient attributes. Moreover, the structure of these models makes them adequate to be used in a model-based closed loop automatic propofol administration system.

\section{Data}

The clinical database [4] used in this study is collected with RugLoopII, a TCI and collection software, which controls the syringe pumps for propofol (the hypnotic drug) using pharmacokinetic model of Schnider, and for remifentanil (analgesic drug) using pharmakocinetic model of Minto [11]. The data base consists of 84 patients, 56 males and 28 females, undergoing ultrasonographic endoscopy under sedationanalgesia with propofol and remifentanil and Depth of
Anesthesia, DoA, quantified by BIS (A-2000, v3.31 Covidien, USA). The database comprises, for each patient, characteristics such as age, height, weight, gender and LBM which are summarized in Table $1(\mathrm{CV}(\%)=$ standard deviation/ mean $\times 100)$. The database also provides recordings of several variables describing the sedation-analgesia process. In particular, total infused volume and targeted concentration for propofol and remifentanil recorded each $5 \mathrm{sec}$ are available. The infusion propofol concentration was $10 \mathrm{mg} \mathrm{ml}^{-1}$ for all the 84 cases.

Several characteristics of the propofol/remifentanil administration are worth noting. The targeted propofol concentrations, $C T$, are in the range [0.5;4.7] $\mu \mathrm{g} \mathrm{ml}^{-1}$ with an average of $2.2 \mu \mathrm{g} \mathrm{ml}^{-1}$ and a standard deviation of 0.65 $\mu \mathrm{g} \mathrm{ml}^{-1}$. However, there are only 27 target concentrations to which we will refer as 27 clusters. In 46 of the 84 cases the targeted propofol concentrations were readjusted during the clinical procedure up to 11 times, as described in Table 2 . This means that these patients were administrated several boluses. For the 38 patients who did not experience $C T$ readjustment the most frequently targeted propofol concentrations were $1.5,2.0$ and $3.0 \mu \mathrm{g} \mathrm{ml}^{-1}$, respectively 11,14 and 8 times. Note that the boluses range between $0.446 \mathrm{ml}$ and $5.48 \mathrm{ml}$ and are administrated as a series of shots over a time span of several minutes, hereafter denoted by $\Delta t_{\text {bolus }} \in$ $[0.17,1.08]$.The duration of propofol administration varies between 16 and $116 \mathrm{~min}$ with an average of $56 \mathrm{~min}$. Seven of the eighty four patients did not receive remifentanil and for the remaining seventy seven patients, the targeted remifentanil concentrations were in the range $[0.5 ; 3.5] \mathrm{ng} \mathrm{ml}^{-1}$.

\section{Methods}

In a clinical procedure a bolus is administrated in a short period of time, with the purpose of rapidly achieving a

Table 1 Summary statistics of patient characteristics

\begin{tabular}{llllrr}
\hline Patient data & Group & Min & Max & Mean & CV (\%) \\
\hline Age (years) & Total & 19 & 83 & 60.6 & 22.2 \\
& M & 35 & 82 & 61.2 & 20.4 \\
& F & 19 & 83 & 59.5 & 25.8 \\
Height (cm) & Total & 145 & 192 & 166.9 & 5.7 \\
& M & 151 & 192 & 171.4 & 4.5 \\
& F & 145 & 165 & 158.0 & 3.4 \\
Weight (Kg) & Total & 41 & 119 & 69.9 & 20.6 \\
& M & 53 & 119 & 72.5 & 19.7 \\
& F & 41 & 90 & 64.7 & 20.5 \\
LBM [7] (Kg) & Total & 32.7 & 76.1 & 51.89 & 17.1 \\
& M & 44.3 & 76.1 & 56.21 & 13.0 \\
& F & 32.7 & 50.4 & 43.26 & 9.5 \\
\hline
\end{tabular}


Table 2 Distribution of the number of different targeted propofol concentrations (n $C T$ ) per patient

\begin{tabular}{llllllllllll}
\hline n $C T$ & 1 & 2 & 3 & 4 & 5 & 6 & 7 & 8 & 9 & 10 & 11 \\
n patients & 38 & 9 & 6 & 10 & 8 & 1 & 5 & 0 & 4 & 1 & 2
\end{tabular}

physiological state. The bolus of propofol that each patient receives depends not only on the targeted propofol concentration and the patient own characteristics but also on his previous state. For each case or individual there is one measure, the initial bolus and there may be more measures for those individuals for whom the target concentration needed readjustment. Although there are repeated measures for some individuals, these are not correlated. Thus, the dataset for the bolus may be looked upon as a cross sectional dataset and the objective is to express the bolus $\boldsymbol{Y}$ as a linear (in the parameters) function of the patient characteristics represented by the linear regression equation:

$\boldsymbol{Y}=\boldsymbol{X} \boldsymbol{\beta}+\boldsymbol{\epsilon}$

where the design matrix $\boldsymbol{X}$ contains:

- information on the patient-the patient age in years, Age; the patient weight in kilograms, Weight; the patient height in centimeters, Height; the lean body mass in kilograms, $L B M$;

- target propofol concentration, $C T$;

- information on the previous state of the patient:

- the required increment on target propofol concentration, $\Delta C T(>0)$, at the beginning $\triangle C T=C T$;

- whether it is the first bolus, coded by a dummy variable

Dum $= \begin{cases}1, & \text { if is an initial bolus } \\ 0, & \text { otherwise }\end{cases}$

- interaction terms

and $\epsilon$ is a vector of zero mean random variables with diagonal covariance matrix with entries $\sigma_{i}^{2}$ and represents the unobserved random errors.

Now, concerning the continuous infusion rate, the data structure is quite different: for each patient the infusion rate (computed from the total infused volume) and target concentration for propofol are available each $5 \mathrm{sec}$. Obviously, the infusion rate is correlated over time and thus this data set constitutes a longitudinal dataset. Longitudinal datasets in which the behavior of entities are observed across time [2] have both the cross-sectional and time series dimensions and allow the study of individual dynamics as well as the time ordering of events. There are several models available on the literature for longitudinal data and in this work we consider random effects population models that explicitly contain a time-constant unobserved effect, [18]. Let $y_{i t}$ be the infusion rate of the $i$ th patient at time $t$ and let $\boldsymbol{X}_{i t}$ be the design matrix that contains, for each $t$, not only variables pertaining information on the patient and target propofol concentration but also information concerning the time elapsed since the beginning of propofol administration, $t$, in seconds and the time elapsed since the last change in the target concentration $C T, t_{\triangle C T}$ plus interactions. Then

$y_{i t}=\alpha+\boldsymbol{X}_{i t} \boldsymbol{\beta}+v_{i t}$

where $v_{i t}=v_{i}+\epsilon_{i t}$ are the cluster-specific intercepts. For each $t, v_{i t}$ is the sum of the unobserved effect, $v_{i}$, with an idiosyncratic error, $\epsilon_{i t}$, which describes variations over individuals and time.

To assess the performance of the models the dataset is randomly divided into a training set with 74 cases and a test set with the remaining 10 cases. The models are calibrated using the training set and residual analysis are carried out to study the quality of the fit of the models. To assess the predictive performance of the models root mean squared errors and mean absolute error are computed for the 10 cases in the test set.

\section{Results}

\subsection{Model for the boluses}

A propofol bolus in milliliters, bolus, is obtained from the model described by the following equation,

$$
\begin{aligned}
\text { bolus }= & \beta_{0}+\beta_{1} \text { Weight }+\beta_{2} \text { Height }+\beta_{3} L B M+\beta_{4} C T \\
& +\beta_{5} \Delta C T+\beta_{6} \text { Age } \cdot \Delta C T+\beta_{7} \text { Dum } \cdot C T .
\end{aligned}
$$

Estimates for the coefficients of the model using the training set by ordinary least squares (OLS) allowing for heteroscedasticity [18] via White estimates of standard errors are given in Table 3. The estimated model presents a coefficient of determination $R^{2}=0.98$, i.e, $98 \%$ of the variation of propofol bolus around its mean is explained by the variables. To further assess the quality of the fit the probability density of the error, estimated using a normal kernel density estimation with 100 equally spaced points (MATLAB 7.10.0(R2010a)) is plotted in Fig. 1. The errors are symmetricaly distributed around the value zero. Moreover, there is no correlation between the errors and the boluses indicating a valid model.

To interpret the model we start by analyzing the sign of the coefficients associated to the information on the patient: the coefficients $\beta_{1}$ and $\beta_{2}$ associated with weight and height, respectively, are positive indicating that heavier and taller patients need more bolus; the coefficients $\beta_{3}$ and $\beta_{6}$ associated with LBM and age, respectively, are negative indicating that higher LBM as well as older age lead to decreased bolus. 
Table 3 Estimated coefficients

\begin{tabular}{lcc}
\hline Variable & Coefficient & $p$ value \\
\hline 1 & -2.091 & 0.0010 \\
Weight & 0.01936 & 0.0000 \\
Height & 0.01441 & 0.0052 \\
LBM & -0.03152 & 0.0000 \\
CT & 0.1664 & 0.0000 \\
$\Delta C T$ & 2.140 & 0.0000 \\
Age $\cdot \Delta C T$ & -0.005657 & 0.0000 \\
Dum $\cdot C T$ & -0.3407 & 0.0007
\end{tabular}

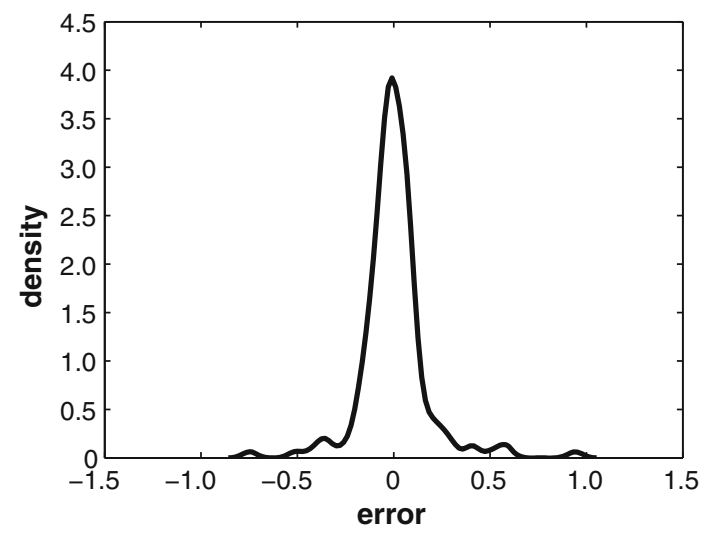

Fig. 1 Estimated density function of the error on bolus estimation based on (3)

Analyzing the coefficients $\beta_{4}, \beta_{5}, \beta_{6}$ and $\beta_{7}$ it is easy to conclude that the bolus increases with the target propofol concentration, $C T$. Moreover, that increase is larger for younger age patients.

Model (3) is now applied to predict the bolus for the test set. In this set there are 10 cases corresponding to 10 initial and 20 intermediate bolus. The observed errors range from -0.165 to $0.191 \mathrm{ml}$ with a mean of -0.007 and a standard deviation of $0.088 \mathrm{ml}$, corresponding to absolute percentage errors between 0.3 and $24 \%$ with a mean of $6 \%$. The error analysis is consistent with a good performance of the model. To further illustrate this finding, Fig. 2 represents the bolus as a mean infusion rate over the observed $\Delta t_{\text {bolus }}$ for case 9 which is particularly interesting since there are multiple target concentration changes.

\subsection{Model for the infusion rate of propofol}

Now, the objective is to model the infusion rate during the continuous drug administration, $I R_{t}$.

The training data set constitutes a longitudinal (or panel) data set and the model under consideration is of the form (2). The model is estimated by OLS assuming that neither the temporal nor the individual effects are statistically

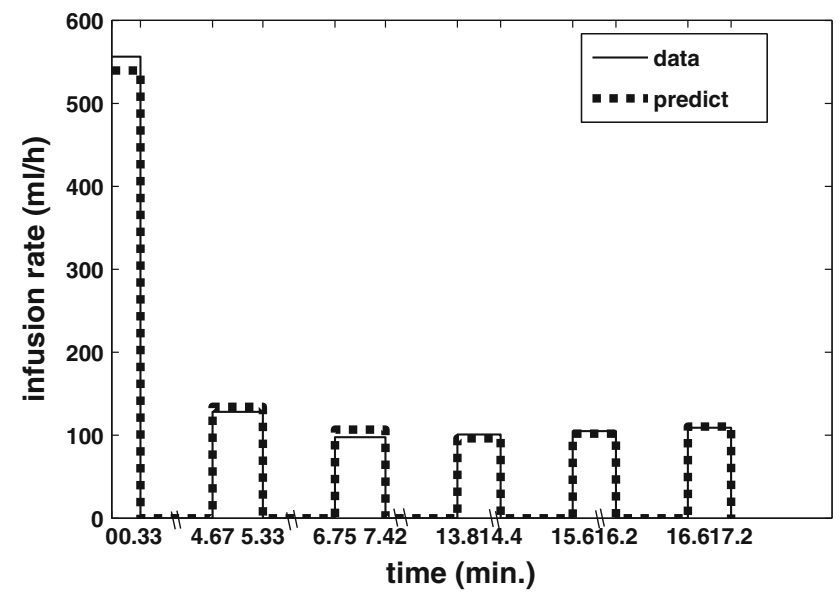

Fig. 2 Mean infusion rate for propofol bolus from the test set-case 9

significant, Pooled OLS, allowing for heteroscedasticity between clusters which are identified by the target concentration [18]. Residual analysis indicates the absence of autocorrelation and an approximately symmetrical distribution around zero supporting an adequate model.

The estimated model is described by the following equation with coefficients given by Table 4 :

$$
\begin{aligned}
I R_{t}= & \left(\beta_{1}+\beta_{2} \text { Age }+\beta_{3} \text { Weight }+\beta_{4} \text { Weight }^{2}\right. \\
& \left.+\beta_{5} \text { Height } \cdot \text { Weight }+\beta_{6} L B M \cdot \text { Weight }\right) \cdot C T_{t} \\
& +\left(\beta_{7} \text { Age }+\beta_{8} \text { Height }+\beta_{9} C T_{t}+\beta_{10} C T_{t} \cdot t\right. \\
& \left.+\beta_{11} C T_{t} \cdot t^{2}\right) \cdot t+\left(\beta_{12} \text { Age }+\beta_{13} C T_{t}\right. \\
& \left.+\beta_{14} \text { Height } \cdot t_{\Delta C T}+\beta_{15} \text { Age } \cdot t_{\Delta C T}\right) \cdot t_{\Delta C T},
\end{aligned}
$$

where $I R_{t}$ is the infusion rate of propofol $\mathrm{in} \mathrm{ml} \mathrm{hr}^{-1}$ at time $t$.

Table 4 Estimated coefficients

\begin{tabular}{lll}
\hline Variable & Coefficient & $p$ value \\
\hline CT & 19.289 & 0.000 \\
Age $\cdot C T$ & -0.078958 & 0.000 \\
Weight $\cdot C T$ & -0.16257 & 0.000 \\
Weight ${ }^{2} \cdot C T$ & 0.0021733 & 0.000 \\
Height $\cdot$ Weight $\cdot C T$ & 0.0022762 & 0.000 \\
LBM $\cdot$ Weight $\cdot C T$ & -0.0053415 & 0.000 \\
Age $\cdot t$ & 0.0000463 & 0.000 \\
Height $\cdot t$ & -0.0000224 & 0.000 \\
$C T \cdot t$ & -0.0038381 & 0.000 \\
$C T \cdot t^{2}$ & $1.01 \mathrm{E}-06$ & 0.000 \\
$C T \cdot t^{3}$ & $-8.28 \mathrm{E}-11$ & 0.000 \\
Age $\cdot t_{\Delta C T}$ & 0.0000183 & 0.000 \\
CT $\cdot t_{\Delta C T}$ & -0.0006188 & 0.000 \\
Height $\cdot t_{\Delta C T}^{2}$ & $3.44 \mathrm{E}-09$ & 0.003 \\
Age $\cdot t_{\Delta C T}^{2}$ & $-8.23 \mathrm{E}-09$ & 0.005 \\
\hline
\end{tabular}


Fig. 3 The predicted and the infused rates (left), and the corresponding effect-site concentration (right) for a case with a single target propofol concentration, $C T$-case 4
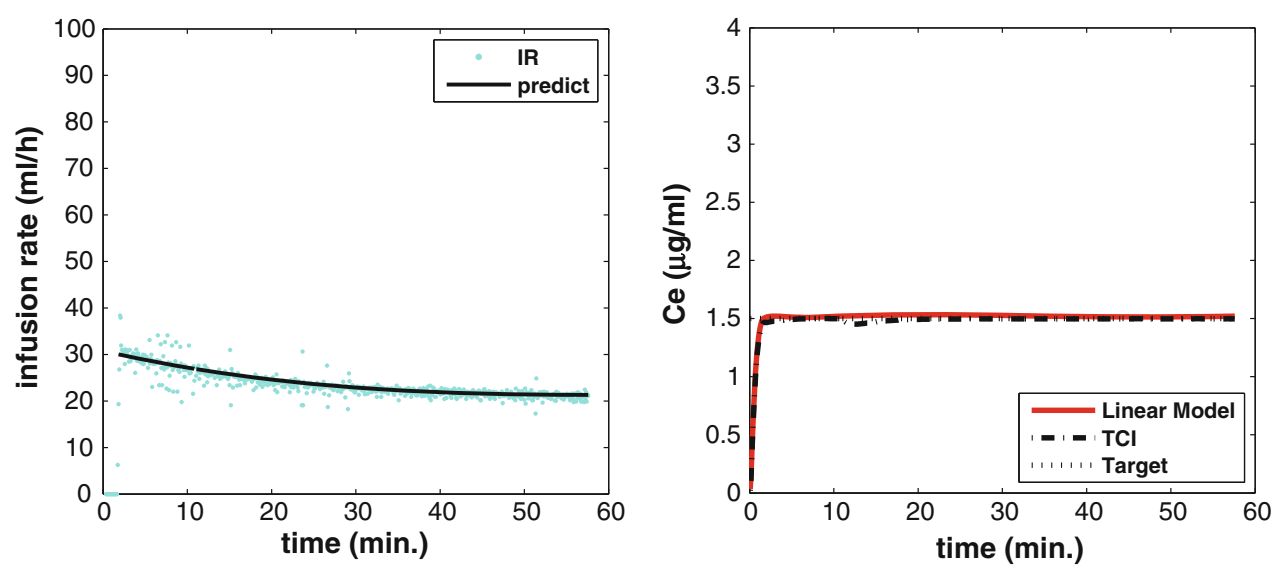

Fig. 4 The predicted and the infused rates (left), and the corresponding effect-site concentration (right) for a case with two values for target propofol concentration, $C T$ case 3

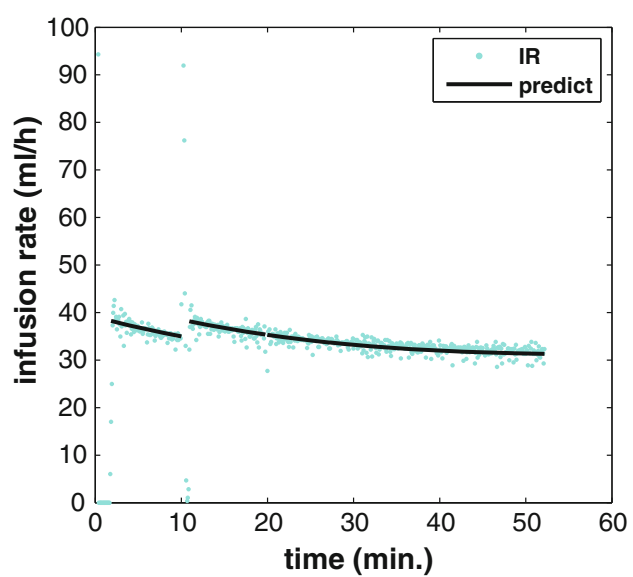

Model (4) may be rewritten as (5) with $t_{\Delta C T}=t-k$, where $k$ represents the instant of target concentration $C T$ readjustment.

$$
\begin{aligned}
I R_{t}= & {\left[\left(\beta_{1}+\beta_{2} \text { Age }+\beta_{3} \text { Weight }+\beta_{4} \text { Weight }^{2}\right.\right.} \\
& \left.\left.+\beta_{5} \text { Height } \cdot \text { Weight }+\beta_{6} L B M \cdot . . \text { Weight }\right) \cdot C T_{t}\right] \\
& +\left[\left(\beta_{14} \text { Height }+\beta_{15} \text { Age }\right) k^{2}-\left(\beta_{12} \text { Age }+\beta_{13} C T_{t}\right) k\right] \\
& +\left[\left(\beta_{7} \text { Age }+\beta_{8} \text { Height }+\beta_{9} C T_{t}+\beta_{12} \text { Age }+\beta_{13} C T_{t}\right.\right. \\
& -2 k\left(\beta_{14} \text { Height.. }+\beta_{15} \text { Age }\right)+\left(\beta_{10} C T_{t}+\beta_{14}\right. \text { Height } \\
& \left.\left.\left.+\beta_{15} \text { Age }\right) t+\beta_{11} C T_{t} \cdot t^{2}\right) t\right] .
\end{aligned}
$$

It is now easy to see three main components of the infusion rate at time $t$ (delimited by [ ]). The first, which may be called the baseline depends on the patient characteristics and the instant target concentration; the second results from a readjustment of target concentration and alters the baseline component; finally the third models a time dependent dynamic component of $I R_{t}$.

From the analysis of the coefficients and based on the range of the variables, results the following model interpretation:
- at the beginning and for a null target concentration the infusion rate is zero;

- the baseline increases with the target propofol concentration and the increase is larger for heavier, taller and younger patients as well as patients with lower LBM;

- the time dependent dynamic component is nonlinear but exhibits a decreasing trend; however, if the clinical intervention is long and depending on patient characteristics, the infusion rate may present an increasing trend for several minutes, reverting to the decreasing trend afterwards;

- as before, higher target concentration, taller stature and young age contribute to increase the initial velocity of the infusion rate decrease.

To assess its predictive performance model (4) is applied to the test set. The root mean squared error, RMSE, and the mean absolute error are computed for the 10 cases. The RMSE varies between 1.11 and $6.76 \mathrm{ml} \mathrm{hr}^{-1}$ and the absolute percentage error between 3 and $9 \%$.

To further illustrate the good performance of the models (3) and (4), the effect-site concentrations induced by propofol administered by these models and by TCI are computed 
Fig. 5 The predicted and the infused rates (left), and the corresponding effect-site concentration (right) for a case with a single target propofol concentration, $C T$, corresponding to a cluster not included in the training setcase 7
Fig. 6 The predicted and the infused rates (left), and the corresponding effect-site concentration (right) for a case with several readjustments of the target propofol concentration, $C T$ - case 9 Fig. 2
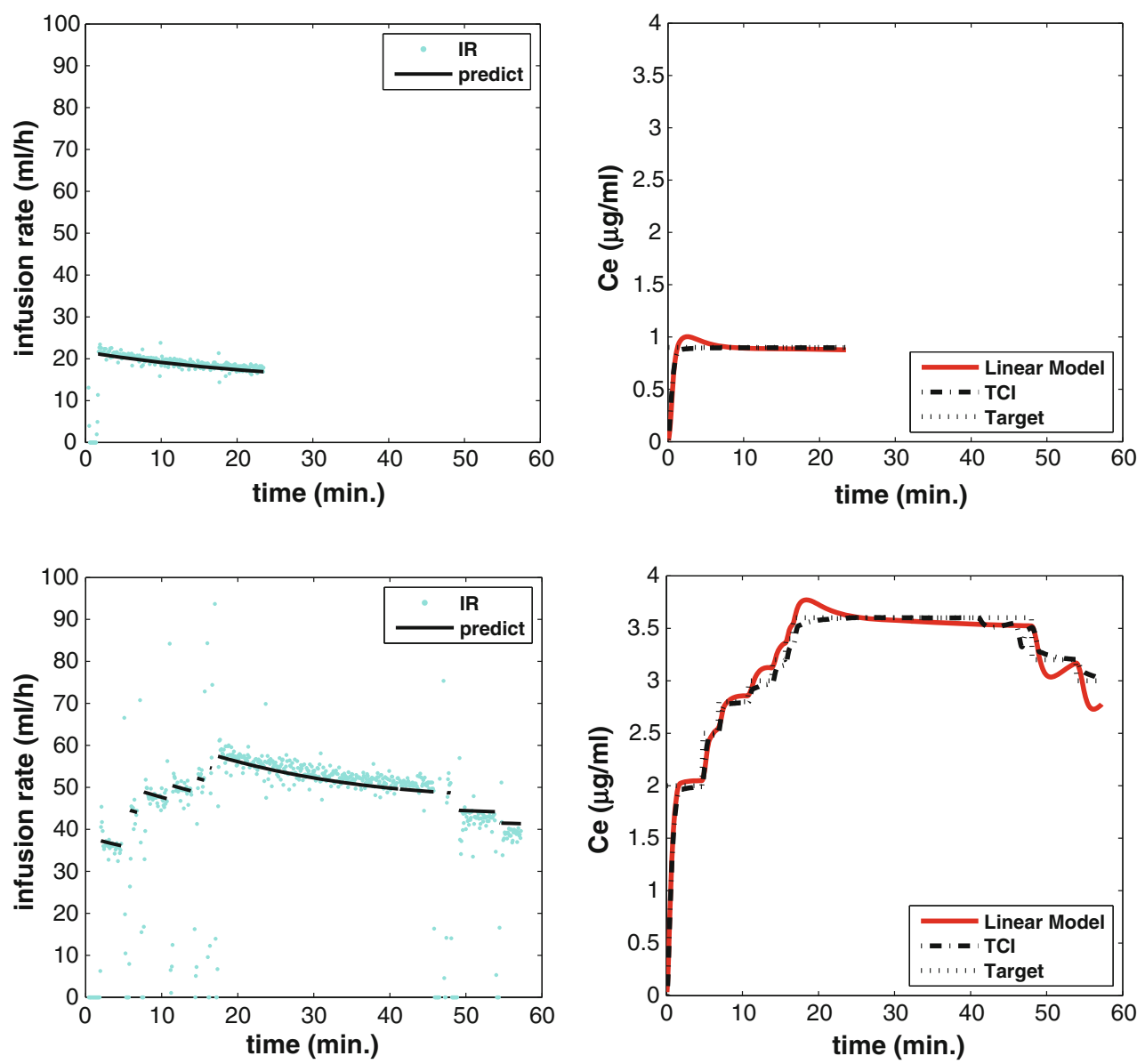

Table 5 Factor range use in the sensitivity analysis

\begin{tabular}{lll}
\hline Factor & Min & Max \\
\hline Age (years) & 19 & 90 \\
Height $(\mathrm{cm})$ & 140 & 195 \\
Weight $(\mathrm{Kg})$ & 40 & 120 \\
$\mathrm{CT}\left(\mu \mathrm{ml}^{-1}\right)$ & 0.5 & 6.0 \\
\hline
\end{tabular}

adopting exactly the same procedure. Figures 4, 5, 6 present the predicted and the infused rates (left), and the corresponding effect-site concentrations (right), for four cases from the test set. Figure 5 which represents the predicted and the infused rates (left), and the corresponding effect-site concentration (right) for case 7 deserves special attention. In fact, although the target propofol concentration, $C T$, for case 7 corresponds to a cluster not included in the training set, the predict performance of the model is comparable with the remaining cases on the test set $(R M S E=5.38, M A P E=7 \%)$.

\section{Sensitivity analysis}

To determine which factors contribute most to output variability, a sensitivity analysis is conducted using the

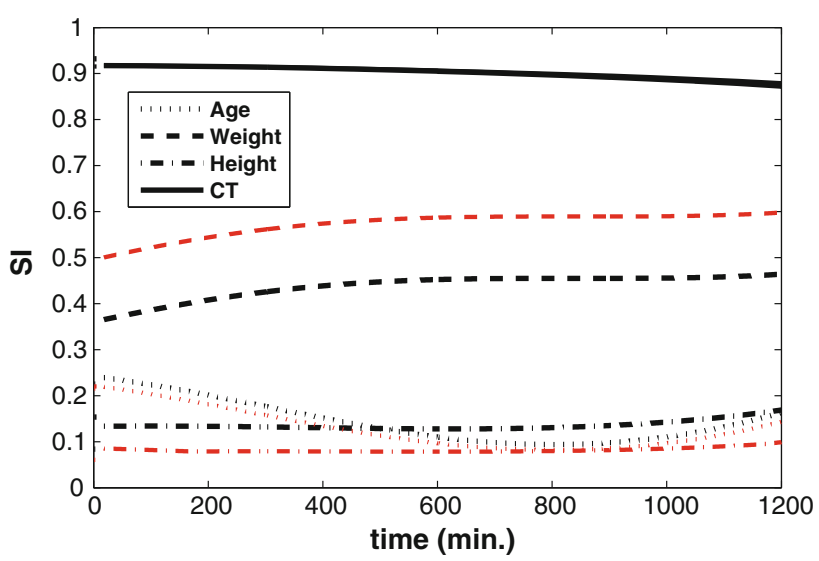

Fig. 7 Time evolution of the Sensitivity Index for the Linear model. More dense and dark line for male and less dense line for female

sensitive index which provides an indication of parameter and model variability [8].

The sensitivity index, $S I$ is defined as the relative difference in the output when one input parameter is varied from its minimum to its maximum value [8]. Thus, in the case under study here, $S I$ is defined as 


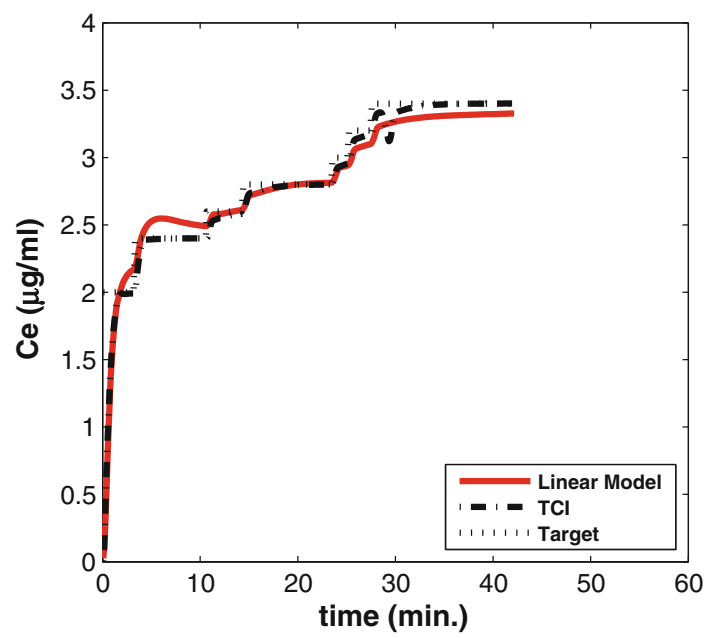

Fig. 8 Time evolution of the two effect-site concentrations corresponding to the dosage profiles of PL model and TCI system along with the target concentration programmed for a female with 76 years old, weighing $54 \mathrm{~kg}, 145 \mathrm{~cm}$ height and corresponding LBM of $37 \mathrm{~kg}$

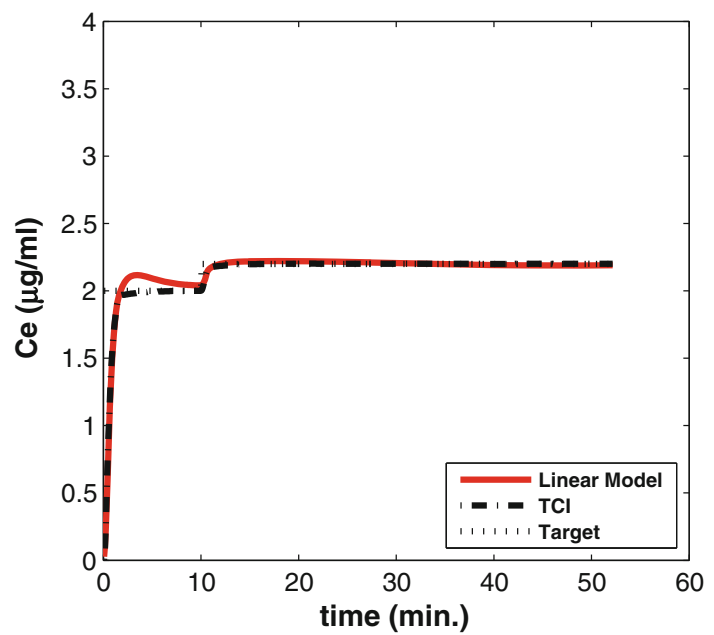

Fig. 9 Time evolution of the two effect-site concentrations corresponding to the dosage profiles of PL model and TCI system along with the target concentration programmed for a female with 69 years old, weighing $59 \mathrm{~kg}, 156 \mathrm{~cm}$ height and corresponding LBM of $42 \mathrm{~kg}$

$S I=\frac{I R_{\max }-I R_{\min }}{I R_{\max }}$,

where $I R_{\max }$ and $I R_{\min }$ correspond to, respectively, the maximum and the minimum of the infusion rate resulting from varying the factor over its entire range. The ranges for factors Age, Height and Weight considered in this section and reported in Table 5 result from the ranges observed in the data set and reported in Table 1. The range for CT reported in Table 5 is wider than that reported in Table 1 for the data set but has been observed in recent surgeries and is clinically accepted.

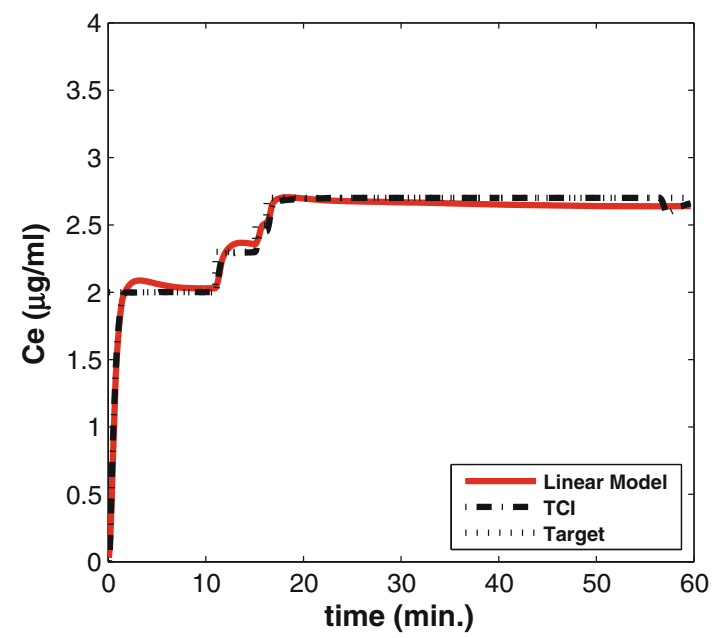

Fig. 10 Time evolution of the two effect-site concentrations corresponding to the dosage profiles of PL model and TCI system along with the target concentration programmed for a male with 61 years old, weighing $74 \mathrm{~kg}, 182 \mathrm{~cm}$ height and corresponding LBM of $60 \mathrm{~kg}$

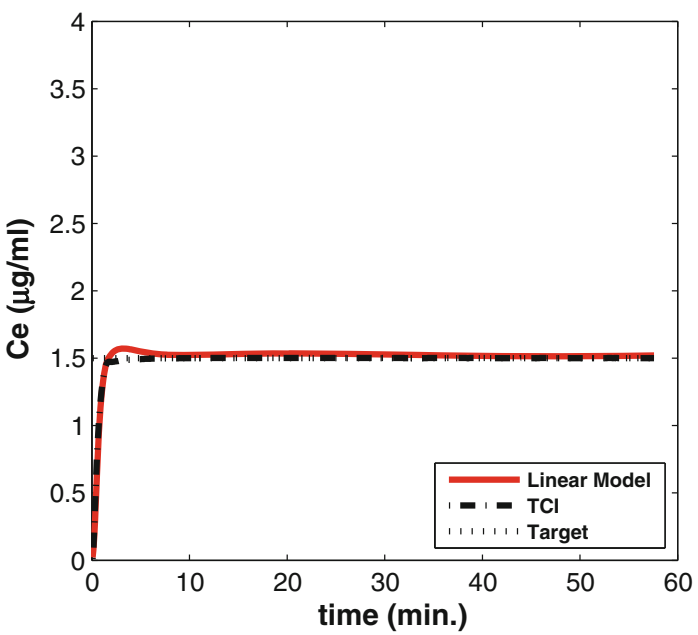

Fig. 11 Time evolution of the two effect-site concentrations corresponding to the dosage profiles of PL model and TCI system along with the target concentration programmed for a male with 57 years old, weighing $65 \mathrm{~kg}, 174 \mathrm{~cm}$ height and corresponding LBM of $54 \mathrm{~kg}$

Figure 7 represents the time evolution of SI for each factor, age, height, weight and CT by gender. The results indicate that the factor that contributes most to the infusion rate variability is the target propofol concentration, CT with a similar $S I$ values for men and women. Among the remaining three factors, age, weight and height, weight is the one that presents the highest sensitivity index and also the one which differs most between the genders. It is noteworthy that SI for the factor weight is about $10 \%$ larger for women. The results also indicate that $S I$ for the factor age decreases in the first hour and for the other factors is approximately constant over time. 
Thus, these results indicate that the infusion rate is sensitive essentially to the target concentration, CT and the weight of the patient.
The dosage profile here proposed for the PL model is described by Algorithm 1.

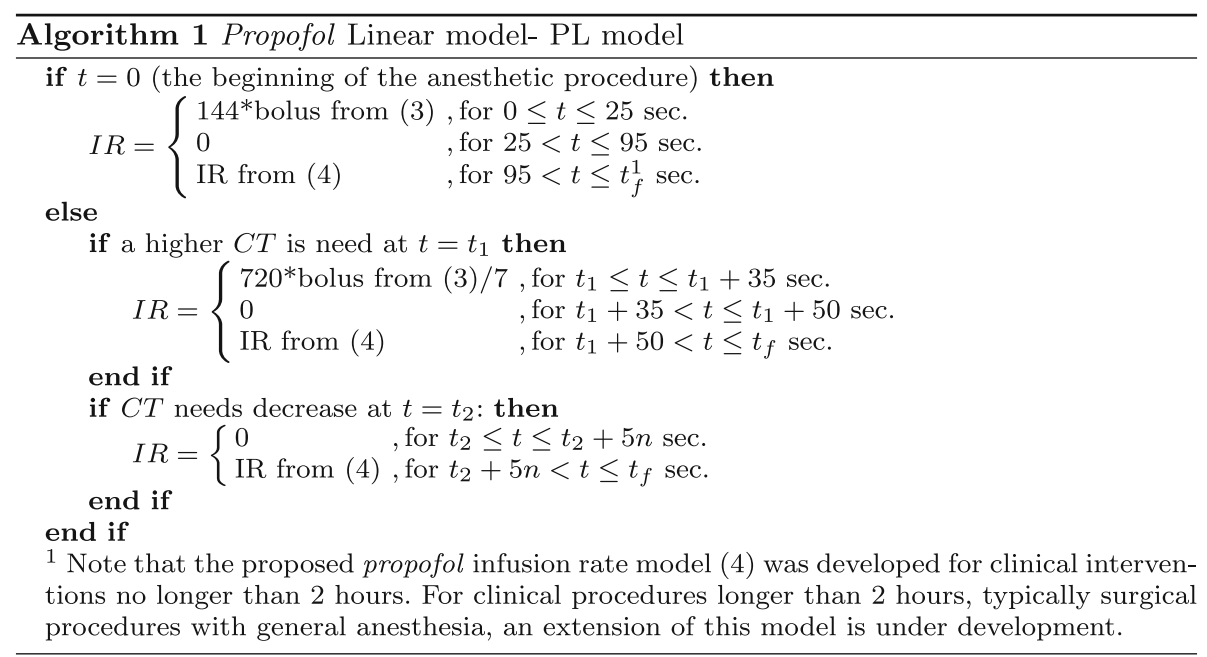

\section{The propofol linear model: PL model}

In this section the Linear model for propofol dosage is proposed. In order to complete the profile dosage and fully specify the model, a procedure for propofol administration both to increase and decrease $C T$ is needed. To increase $C T$, the rate at which the boluses are administrated as well as the moment at which the continuous infusion administration must start are defined based on mean values of the database. Thus,

- an interval of 25 and $35 \mathrm{sec}$ is adopted for the initial and subsequent, respectively, boluses administration;

- the continuous infusion administration starts $95 \mathrm{sec}$ after the initialization of propofol administration (anesthetic procedure) and $50 \mathrm{sec}$ after an increase in CT.

On the other hand, to decrease $C T$ it is necessary to cease propofol administration during a time interval that depends on the previous $C T$ and the new $C T$. Based on the database information, the number of observations without propofol administration, $n$, may be expressed as a linear function of the logarithm of the ratio between the two target concentrations. Using a simple linear regression the following model is obtained

$n=[66.219 * \log ($ previous $C T /$ new $C T)+3.479]$,

with [.] denoting the largest whole number contained. This model (7) presents a coefficient of determination $R^{2}=0.94$.

\section{PL model vs TCI}

7.1 PL model vs schnider model

The results obtained so far indicate that the PL model represented by Algorithm 1, developed in Sect. 4 is able to predict bolus and infusion rates comparable to those of TCI. However, since effect-site concentrations resulting from the dosages are

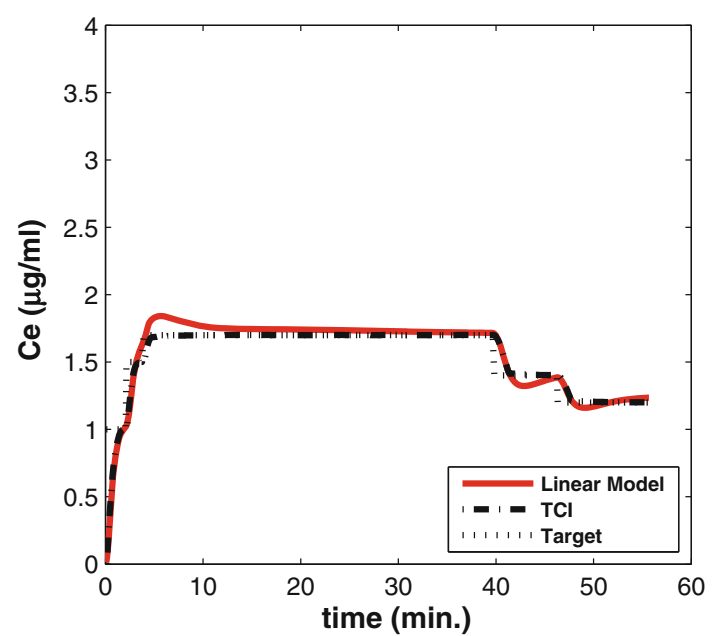

Fig. 12 Time evolution of the two effect-site concentrations corresponding to the dosage profiles of PL model and TCI system along with the target concentration programmed for a male with 71 years old, weighing $65 \mathrm{~kg}, 169 \mathrm{~cm}$ height and corresponding LBM of $53 \mathrm{~kg}$ 


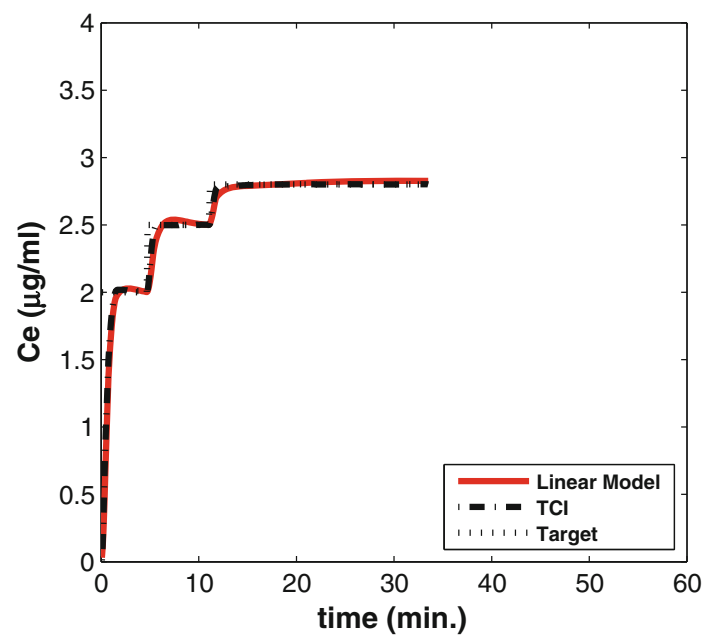

Fig. 13 Time evolution of the two effect-site concentrations corresponding to the dosage profiles of PL model and TCI system along with the target concentration programmed for a male with 44 years old, weighing $76 \mathrm{~kg}, 178 \mathrm{~cm}$ height and corresponding LBM of $60 \mathrm{~kg}$

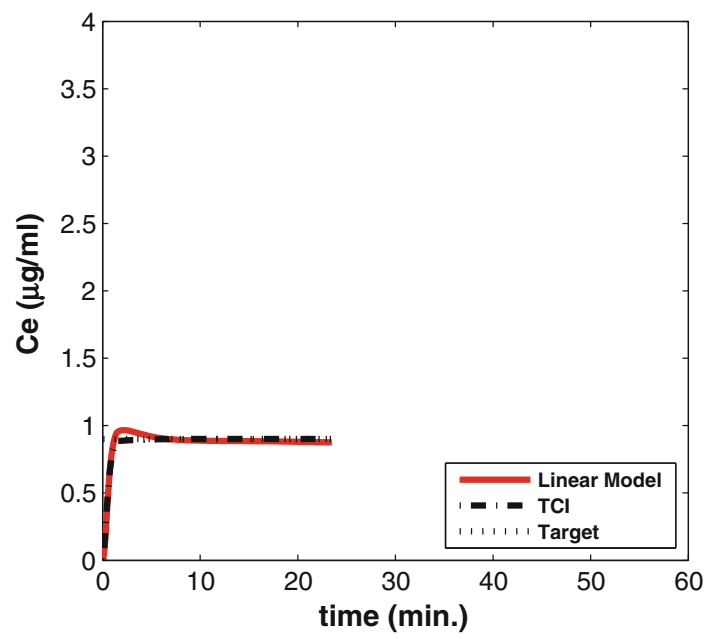

Fig. 14 Time evolution of the two effect-site concentrations corresponding to the dosage profiles of PL model and TCI system along with the target concentration programmed for a male with 56 years old, weighing $102 \mathrm{~kg}, 192 \mathrm{~cm}$ height and corresponding LBM of $76 \mathrm{~kg}$

important, the purpose of this section is to compare the effectsite concentrations resulting from the Linear model and the Schnider model. A design of experiments to perform this comparison cannot be made with the dosage obtained from the Schnider model since the authors do not have access to a TCI device which implements this model. For this reason the comparison between the two models will be conducted on the 10 cases of the test set.

Based on all the ten graphics represented in Figs. 8, 9, 10, $11,12,13,14,15,16,17$ of the time evolution of the two effect-site concentrations, corresponding to the dosage profiles of PL model and TCI system, along with the target concentration programmed by the clinician we may say that:

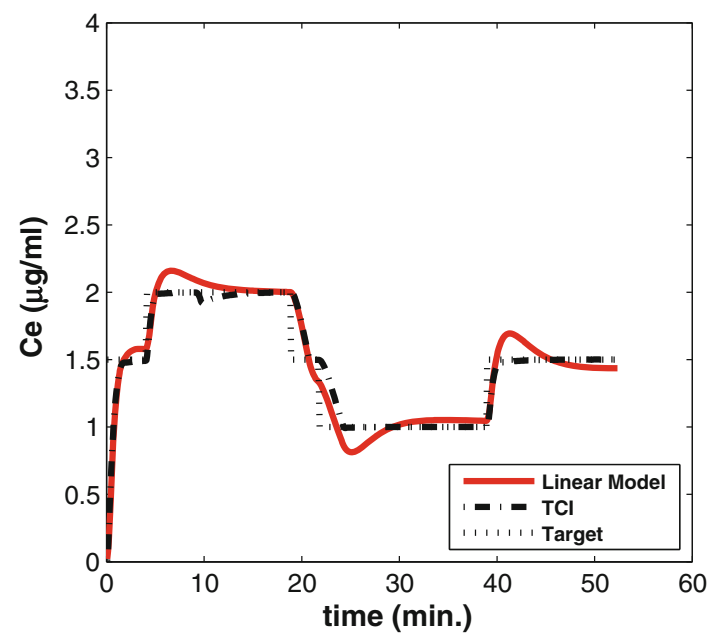

Fig. 15 Time evolution of the two effect-site concentrations corresponding to the dosage profiles of PL model and TCI system along with the target concentration programmed for a male with 72 years old, weighing $80 \mathrm{~kg}, 170 \mathrm{~cm}$ height and corresponding LBM of $60 \mathrm{~kg}$

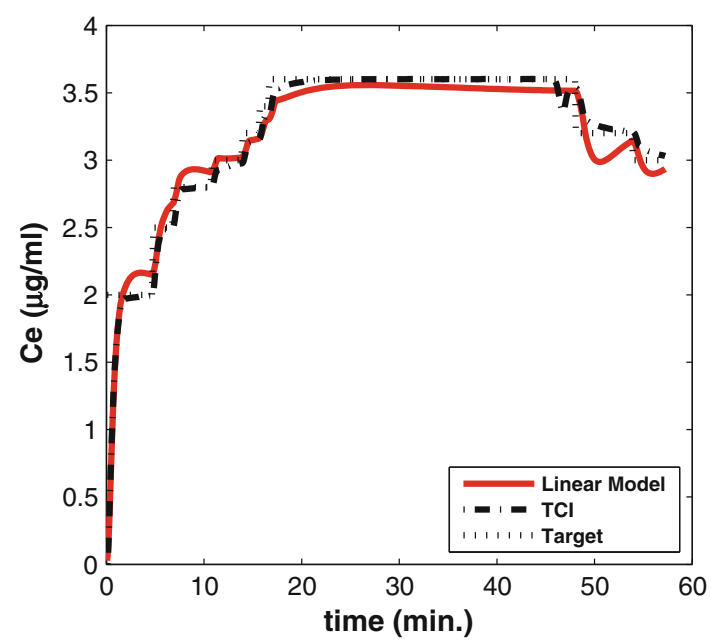

Fig. 16 Time evolution of the two effect-site concentrations corresponding to the dosage profiles of PL model and TCI system along with the target concentration programmed for a male with 71 years old, weighing $61 \mathrm{~kg}, 172 \mathrm{~cm}$ height and corresponding LBM of $51 \mathrm{~kg}$

- the PL model has a performance very similar to the performance of the TCI programmed with the Schnider model;

- small differences between the two models are detected for a short time after some target concentration, $C T$, changes.

\subsection{PL model vs marsh model}

In this section and to compare the effect-site concentrations resulting from the PL model and the Marsh model, a TCI 


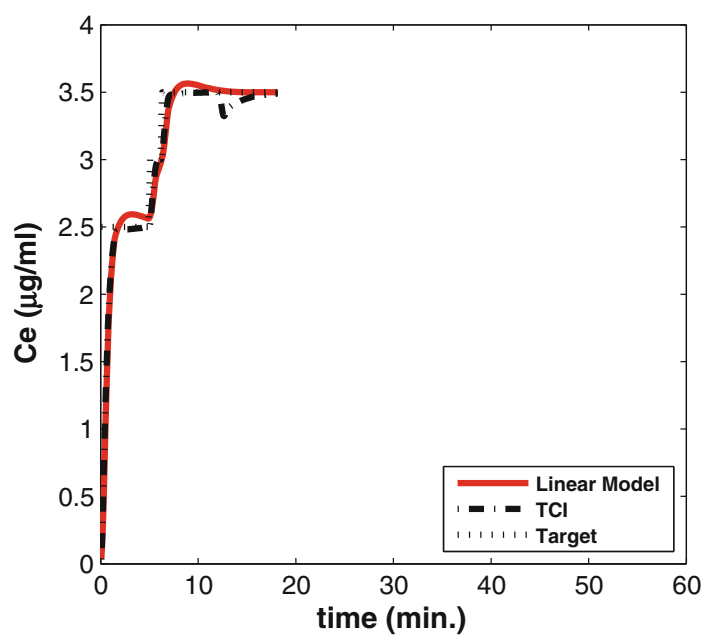

Fig. 17 Time evolution of the two effect-site concentrations corresponding to the dosage profiles of PL model and TCI system along with the target concentration programmed for a male with 60 years old, weighing $76 \mathrm{~kg}, 169 \mathrm{~cm}$ height and corresponding LBM of $58 \mathrm{~kg}$
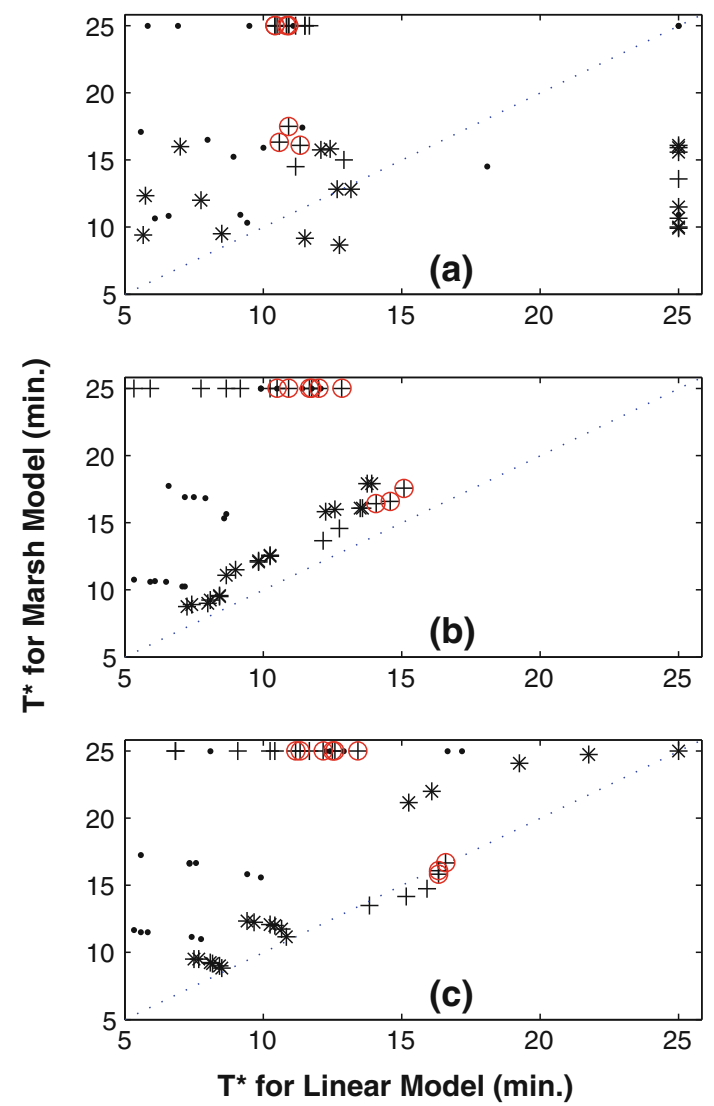

Fig. 18 Elapsed time to attain a stable concentration for different target concentration: $0.5 \mu \mathrm{g} \mathrm{ml}^{-1},(\mathbf{a}), 2.2 \mu \mathrm{g} \mathrm{ml}^{-1}$, (b), and $6.0 \mu \mathrm{g}$ $\mathrm{ml}^{-1}$, (c). The circle identifies cases with LBM greater than the maximum LBM referred in [1]

device is used to compute the infusion rate for each case comprising a set of CT, age, height, weight and gender, using the Marsh model. Then the model of Schnider is used
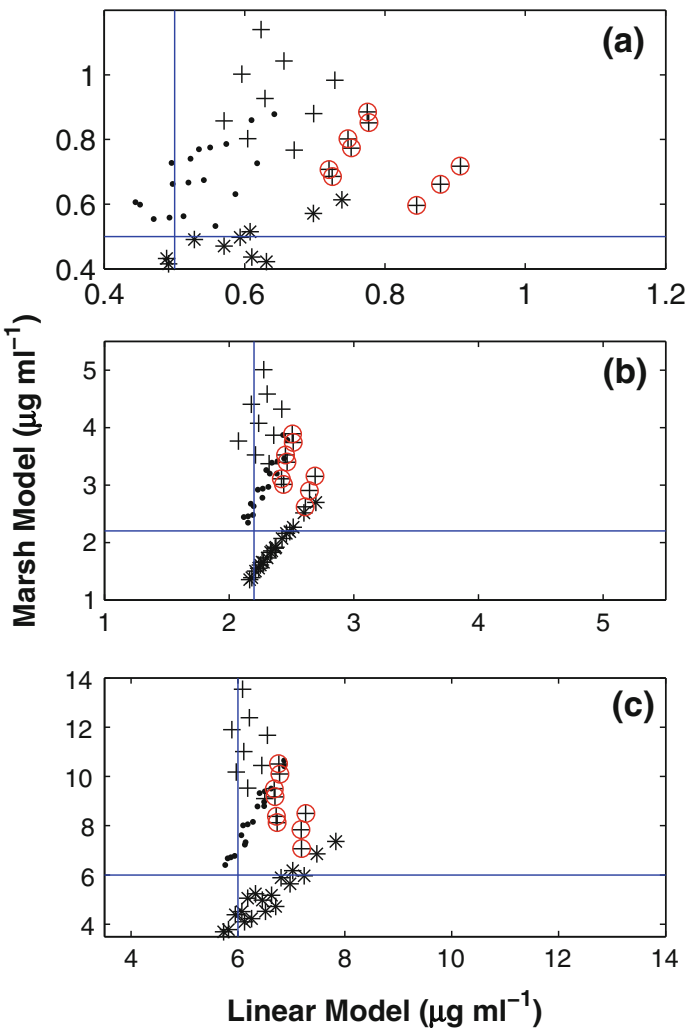

Fig. 19 Maximum concentration in the transient phase for a target concentration of $0.5 \mu \mathrm{g} \mathrm{ml}^{-1},(\mathbf{a}), 2.2 \mu \mathrm{g} \mathrm{ml}^{-1}$, (b), and $6.0 \mu \mathrm{g} \mathrm{ml}^{-1}$, (c). The circle identifies cases with LBM greater than the maximum LBM referred in [1]

to compute the effect-site concentration obtained from the dosages indicated by the TCI and the PL model.

To conduct the comparison between the effect-site concentrations resulting from the two models for the same target concentration value, a factorial design is considered: for each gender, the maximum, minimum and mean value referred in Table 5 (see Sect. 2) is assigned to each factor in a total of 162 cases combinations or cases to be analysed.

To perform a more informative comparison between the two models a division in two phases of the effect-site concentration (time evolution) is considered, the induction phase and a stationary phase. In this analysis three variables will be considered, the time taken by the induction phase, Fig. 18, the maximum concentration on the induction phase, Fig. 19 and the mean error between the target concentration and the effect-site concentration in the stationary phase, Fig. 20. As discussed in [1] the models programmed in the TCI are not valid for values of LBM higher than a given value function of the height. So, in each figure, whenever that happens a circle identifies the case.

Figure 18 are scatter plots of the induction phase duration for both dosages, PL model and Marsh model, for each attributes combination and separated by target concentration: 

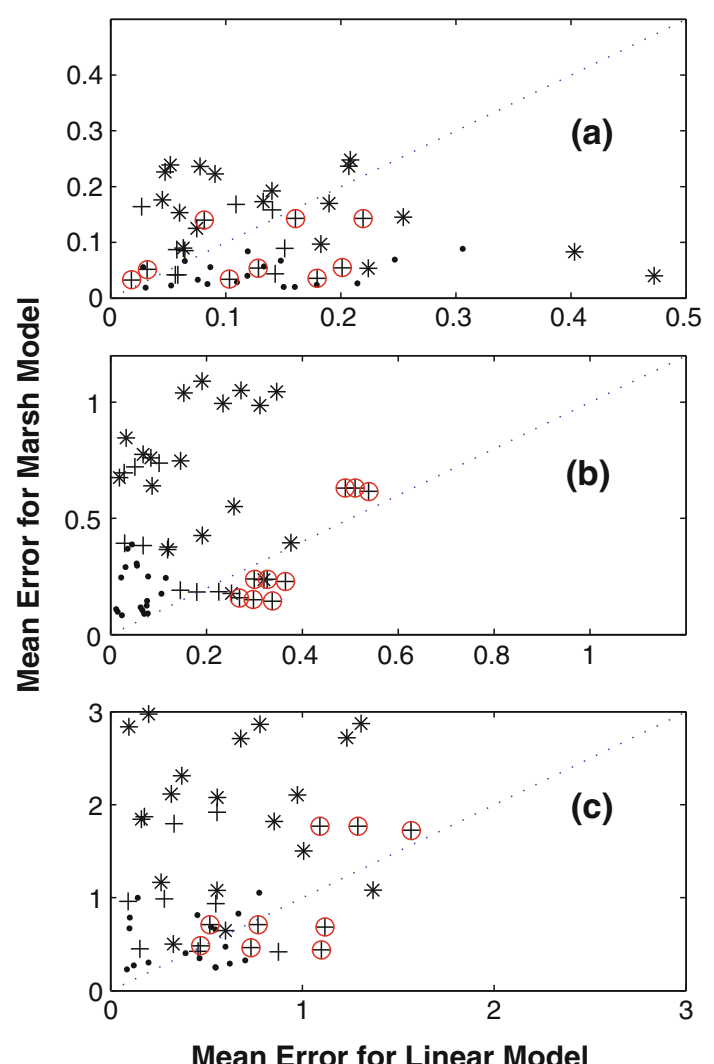

Fig. 20 Mean absolute error in the stationary phase for a target concentration of $0.5 \mu \mathrm{g} \mathrm{ml}^{-1},(\mathbf{a}), 2.2 \mu \mathrm{g} \mathrm{ml}^{-1}$, (b), and $6.0 \mu \mathrm{g} \mathrm{ml}^{-1}$, (c). The circle identifies cases with LBM greater than the maximum LBM referred in [1]

$0.5 \mu \mathrm{g} \mathrm{ml}^{-1}$, (a), $2.2 \mu \mathrm{g} \mathrm{ml}^{-1}$, (b), and $6.0 \mu \mathrm{g} \mathrm{ml} \mathrm{g}^{-1}$, (c). Considering the fact that most points are above the dashed line for all the target concentrations the PL model takes less time to attain the stationary phase. From the analysis of Fig. 19 results the following information:

- for a $40 \mathrm{~kg}$ weight, in the most cases, the Marsh model does not allow to attain the target concentration;

- for a $120 \mathrm{~kg}$ weight the Marsh model leads to maximum effect-site concentrations almost twice the target value;

- the PL model leads to maximum effect-site concentrations near its target value for almost all the cases;

- the PL model presents a relatively higher maximum effectsite concentrations for the lower target concentration.

From Fig. 20 results that the PL model presents a mean absolute error inferior to the one given by the Marsh model for both, mean and maximum, target concentrations. Nevertheless for the target concentration of $0.5 \mu \mathrm{g} \mathrm{ml}^{-1}$, (a), the Marsh model presents results slightly better than the Linear model.

Combining the information of the last three figures the PL model predicts a dosage profile that is faster in leading to an effect-site concentration closer to the target concentration. Nevertheless, both models lead to undesirable results for low target concentrations.

\section{Discussion and conclusions}

Considering that the models used in this work for longitudinal data are the simplest available on the literature, the results are promising. In fact, the objective was not to reproduce the behavior of the TCI administration, but to predict bolus and infusion rates comparable to those of TCI and these issues were clearly achieved. Moreover, the performance of the models in a test set with a broad range of characteristics including interventions with/without target propofol concentration readjustments and new target propofol concentration was satisfactory. Also, the effect of age, height, weight, LBM and the target propofol concentration both on the bolus, model (3), and the infusion rate, model (4), is in agreement with pharmacokinetic principles. The target concentration is the factor that contributes most for the infusion rate variability with a sensitivity index which is similar for both genders. The next factor contributing to the infusion rate variability is the patients weight with a higher sensitivity index for women. The results further indicate that the PL model predicts a dosage profile that leads to an effect-site concentration close to the desired target concentration as fast as TCI's Schnider model. The results obtained so far may be considered a step towards to the definition of a simple model for estimating propofol individualized dosage based on the patient attributes. It is noteworthy that this PL model leads to a unique personalized profile dosage.

Several advantages of the PL model, conveyed by its structure and properties may be highlighted. First, it enables easily the inclusion of other clinical parameters in order to obtain a better representation of individualized patient issues and clinical mindset. Furthermore, it allows straightforwardly the use of other measures for DoA, instead of the target effect concentration $(C T)$, whenever they can be considered as function of $C T$. Moreover, the PL model is specially suited to be used in a model-based closed loop automatic propofol administration system, since there is a wide range of control algorithms for linear systems available which present good stability and robustness properties. Finally, the PL model is a statistical model, thus enabling further inferential procedures, such as confidence intervals and hypothesis testing.

As future work the authors have plans to test this model on larger sedation datasets as soon as they become available.

Acknowledgements This work was supported by FEDER funds through COMPETE-Operational Programme Factors of Competitiveness 
("Programa Operacional Factores de Competitividade") and by Portuguese funds through the Center for Research and Development in Mathematics and Applications (University of Aveiro) and the Portuguese Foundation for Science and Technology ("FCT-Fundação para a Ciência e a Tecnologia"), within projects PEst-C/MAT/UI4106/2011 with COMPETE number FCOMP-01-0124-FEDER-022690 and GALENO Modeling and Control for personalized drug administration, PTDC/SAU$\mathrm{BEB} / 103$ 667/2008. Conceição Rocha acknowledges the grant SFRH/BD/ $61781 / 2009$ by FCT/ESF. The authors thank Pedro Gambus (PhD) and Eric Jensen $(\mathrm{PhD})$ in Proclinic Hospital in Barcelona, Spain for providing the clinical database.

\section{References}

1. Absalom A, Struys M. Overview of target controlled infusions and total intravenous anaesthesia. Academia Press, Gent; 2007.

2. Fahrmeir L, Tutz G. Multivariate statistical modelling based on generalized linear models. Springer, Berlin; 2001.

3. Fechner J, Albrecht S, Ihmsen H, Knoll R, Schwilden H, Schuttler J. Predictability and precision of "target-controlled infusion" (TCI) of propofol with the "Disoprifusor TCI" system. Anaesthesist 1988;47, 663-668.

4. Gambús P, Jensen EW, Jospin M, Borrat X, Martinez Pallí G, Fernández-Candil J, Valencia JF, Barba X, Caminal P, Trocóniz IF. Modeling the effect of propofol and remifentanil combinations for sedation-analgesia in endoscopic procedures using an adaptive neuro fuzzy inference system (ANFIS). Anesthesia and Analgesia 2011;112(2), 331-339.

5. Glen J. The development of 'Diprifusor': a TCI system for propofol. Anaesthesia 1998; 53(Suppl 1), 13-21.

6. Gray J, Kenny G. Development of the technology for 'Diprifusor' TCI systems. Anaesthesia 1998;53(Suppl 1): 22-27.

7. Hallynck T, Soep H, Thomis J, Boelaert J, Daneels R, Dettli L. Should clearance be normalised to body surface or to lean body mass?. Br J Clin Pharmacol. 1981;11(5), 523-26.
8. Hamby DM. A review of techniques for parameter sensitivity analysis of environmental models. Environ Monit Assess 1994;32, 135-154.

9. Leslie K, Clavisi O, Hargrove J. Target-controlled infusion versus manually-controlled infusion of propofol for general anaesthesia or sedation in adults. Cochrane Database of Syst Rev 3 2008; doi:10.1002/14651858.CD006059.pub2.

10. Masui K, Upto RN, Doufas AG, Coetzee J, Kazama T, Mortier EP, Struys MM. The performance of compartmental and physiologically based recirculatory pharmacokinetic models for propofol: a comparision using bolus, continuous, and targetcontrolled infusion data. Anesth Analg 2010;111(2), 368-379.

11. Minto CF, Schnider TW, Shafer SL. Pharmacokinetics and pharmacodynamics of remifentanil: II . model application. Anesthesiology 1997;86, 24-33.

12. Passot S, Servin F, Allary R, Pascal J, Prades J, Auboyer C, Molliex S. Target-Controlled Versus Manually-Controlled Infusion of Propofol for Direct Laryngoscopy and Bronchoscopy. Anesth Analg 2002;94(5), 1212-1216.

13. Schnider TW, Minto CF, Schafer SL, Gambus PL, Andersen C, Goodale DB, Youngs EJ. The influence of age on propofol pharmacodynamics. Anesthesiology 1999;90, 1502-1516.

14. Schraag, S. Theoretical basis of target controlled anaesthesia: history, concept and clinical perspectives. Best Pract Res Clin Anaesthesiol 2001;15(1), 1-17.

15. Struys M, Sahinovic M, Lichtenbelt BJ, Vereecke H, Absalom A. Optimizing intravenous drug administration by applying pharmacokinetic/pharmacodynamic concepts. $\mathrm{Br} \mathrm{J}$ Anaesth 2011;107(1), 38-47. doi:10.1093/bja/aer108.

16. Struys M, Versichelen L, Thas O, Herregods L, Rolly G. Comparison of computer-controlled administration of propofol with two manually controlled infusion techniques. Anaesthesia 1997;52(1), 41-50. doi:10.1111/j.1365-2044.1997.002-az001.x.

17. Swinhoe CF, Peacock JE, Glen JB, Reilly CS. Evaluation of the predictive performance of a 'Diprifusor' TCI system. Anaesthesia 1998,53: 61-67. doi:10.1111/j.1365-2044.1998.53s104.x.

18. Wooldridge JM. Econometric analysis of cross section and panel data. MIT Press, Cambridge; 2002. 